\title{
Abnormalities of lung mechanics in young asthmatic children
}

\author{
ANNE GREENOUGH, B G LOFTUS, JENNY POOL, J F PRICE \\ From the Paediatric Respiratory Laboratory, King's College Hospital, London
}

ABSTRACT Measurements of total compliance of the respiratory system by the weighted spirometer technique and of the functional residual capacity by helium gas dilution were attempted in $86^{N}$ asthmatic children aged $2 \cdot 2-7 \cdot 9$ years. In all but six of the 86 children reliable measurements couldr be obtained. Significantly raised functional residual capacity was detected in children with asthma of all degrees of severity. The compliance of the respiratory system was significantly abnorma $\mathrm{B}$ (reduced) only in children who had symptoms at the time of measurement or who had chronic persistent asthma. The results indicate that these measurements are well tolerated in young asth matic children. Further work needs to be undertaken to assess the value of this technique in follow $\vec{\oplus}$ ing the response to treatment.

Asthma is a common illness in preschool children; the cumulative prevalence in 2-6 year olds may be as much as $30 \%{ }^{1}$ In these children asthma attacks may be more severe, ${ }^{2}$ with an increased rate of hospital admission, ${ }^{3}$ and the response to medication may be smaller $^{4}$ and less predictable ${ }^{5}$ than in older children. Thus the ability to assess, by respiratory function testing, the severity of disease and response to treatment is very desirable.

The forced oscillation technique has been used to measure airways resistance in young children, ${ }^{6}$ and with practice preschool children can use a peak flow meter. ${ }^{7}$ Tests of lung function that depend on forced expiratory manoeuvres or plethysmography are seldom possible in young children. Recently, however, we have adapted the weighted spirometer technique for measurement of compliance of the respiratory system (CRS) for use in such children. This, combined with measurement of functional residual capacity (FRC) by helium gas dilution, can be reliably performed in most children aged 2-7 years. ${ }^{8}$ The aim of the present study was to use the combined FRC and CRS technique in young children with asthma, to determine whether the abnormalities of lung mechanics reported in adults ${ }^{910}$ and older children ${ }^{1113}$ could be detected in this age group.

Address for reprint requests: Dr Anne Greenough, Department of Child Health, King's College Hospital, London SE5 8RX.

Accepted 2 February 1987

\section{Methods}

PATIENTS

Studies were attempted in 86 children ( 29 girls and 572 boys) aged 2.2-7.9 years. All had a history of recur-0 rent wheezing responsive to bronchodilator treatment and were attending the paediatric asthma clinic a King's College Hospital.

For assessing the relationship of FRC and CRS tof disease severity, the children were classified in four? groups according to the treatment they were receiving $x$ at the time of measurement: $1-\beta$ adrenergic agonis ( $\beta$ agonist) as necessary (those with the least severe asthma); 2-regular theophylline or sodium cro윽 moglycate; 3-regular inhaled steroids; 4 -regular inhaled steroids and theophylline (those with the most severe asthma). Groups 2, 3, and 4 in addition were receiving a $\beta$ agonist as necessary). A furthe group (No 5) included any child who had symptomso at the time of measurement, regardless of the treat ment previously received.

The study was approved by King's College Hospi $\stackrel{N}{\omega}$ tal's ethical committee and the parents' consent was obtained.

MEASUREMENT OF FRC AND CRS All children were studied in a sitting position while breathing through a face mask (Medishield) into क्षे water sealed spirometer (Gould Pulmonet 3 ). The face् mask has a semi-inflated diaphragm at its edge tœ improve the seal and was firmly held in position to prevent leaks. An internal carbon dioxide absorber 
and adjustable oxygen supply are incorporated in the spirometer, which has a total volume of 6 litres.

Once an apparently good seal had been achieved (no expired gas could be detected escaping around the face mask) the child was switched into the spirometer in FRC mode. FRC was measured by helium gas dilution and a continuous digital readout was displayed.

After the measurement of FRC, CRS was measured by the weighted spirometer technique. ${ }^{8}$ After a constant end expiratory level on the spirometric volume recording had been established, a $500 \mathrm{~g}$ brass weight was placed on the spirometer bell. This produced a constant positive pressure within the circuit of about $2 \mathrm{~cm} \mathrm{H}_{2} \mathrm{O}$ and increased the end expiratory level. Airway pressure was measured via a side port (Sanborn pressure transducer 268B). The weight was removed when a new stable baseline had been achieved; on its removal the end expiratory level returned to the previous baseline. This procedure was repeated five times during the study period. The combined compliance of the respiratory system and the spirometer circuit were calculated from the mean volume-pressure changes of the five weighted applications. Compliance of the spirometer circuit alone had been estimated beforehand by applying a series of weights to the spirometer bell with the circuit closed. The compliance of the spirometer was then subtracted from the total compliance to give CRS. Volumes were all corrected to BTPS conditions.

By performing the two different measurements a leak in the circuit can always be detected. A leak around the face mask prevents equilibration of helium within the circuit and leads to an upward trend in the spirograph tracing (fig 1). Throughout the measurement of FRC and CRS oxygen is added to the circuit at a rate of $0 \cdot 15-0 \cdot 251 \mathrm{~min}^{-1}$, depending on the size of the child. If oxygen is supplied at a rate in excess of demand this could mask a small constant leak during FRC measurement. After initial adjustment, however, the oxygen flow (indicated by the flow meter) remains constant throughout. A leak would increase and at once become obvious when the weight is added and the circuit pressurised during the measurement of CRS. Thus a leak is exacerbrated and may become apparent for the first time as an upward trend in the baseline when the weight is added. If a leak was demonstrated during the measurement of either FRC or CRS the results of both FRC and CRS measurements were discarded.

All calculations of FRC and CRS were performed on coded traces by one observer, who was unaware of the patients' characteristics.

\section{TIME TO EQUILIBRATION}

As appreciable airway obstruction was expected in these asthmatic children, we measured the maximum possible equilibration time in four healthy children and five asthmatic children without symptoms. The displayed FRC was recorded every 15 seconds and equilibration was assumed when the display showed a change of less than $20 \mathrm{ml}$ over a 30 second period. Once this had been reached the nine children continued to breathe into the spirometer in FRC mode for at least a further minute and again the displayed FRC was noted at 15 second intervals. This was done to assess whether our assumption of equilibration as defined above was justified.

\section{REPRODUCIBILITY}

Reproducibility studies were performed on eight asthmatic children (median age $4 \cdot 7$, range $2 \cdot 9-7 \cdot 4$ years). Six separate measurements of FRC and CRS were

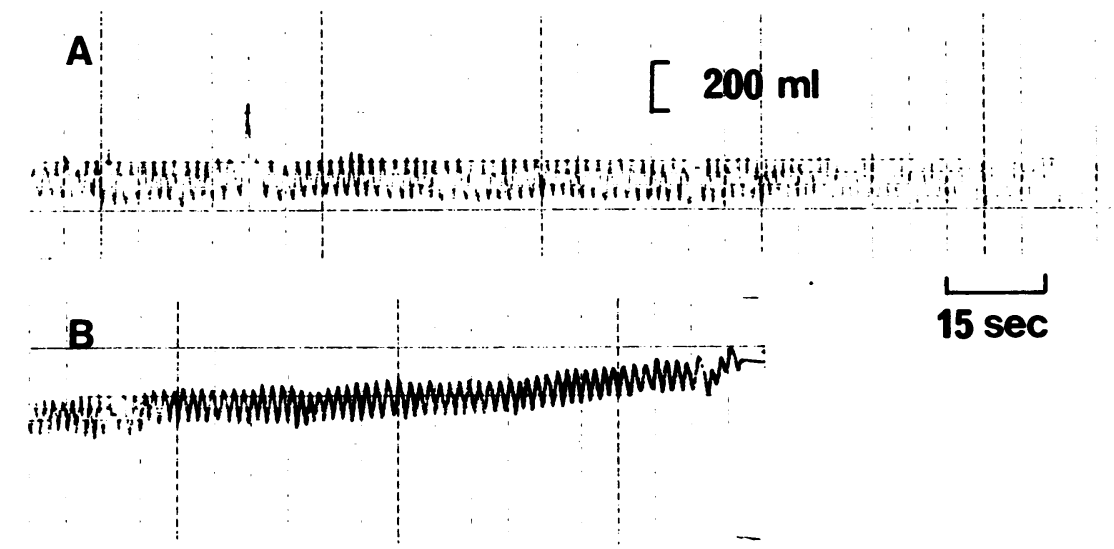

Fig 1 Typical records obtained during measurement of functional residual capacity. Both traces are taken from a 3 year old asthmatic girl. In the lower record $(B)$ there has been a leak around the face mask, shown by the upward trend of the spirograph tracing. No such leak is seen in trace A even though the child was attached to the spirograph for over two minutes. 
made at the same visit to the laboratory in the four older children, and three measurements on each of two successive days in the four younger children (less than $3 \cdot 1$ years).

In addition to the estimation of FRC and CRS, 40 children were asked to attempt a peak flow (PEF) measurement.

\section{STATISTICAL METHODS}

Intrasubject reproducibility was expressed as the coefficient of variation.

To assess the relationship of disease severity to lung function, each measurement was expressed as the number of standard deviations from the mean predicted value ( $z$ scores):

$$
z \text { score }=\frac{\text { measured }- \text { expected (CRS or FRC) }}{\text { SD of normal population }}
$$

The expected CRS, FRC, and SD of a normal population were calculated from our previous results in healthy children aged 2-7 years. ${ }^{8}$

Differences between the asthmatic groups were tested for significance with an unpaired Student's $t$ test.

\section{Results}

\section{EQUILIBRATION TIME}

The maximum time to equilibration in the four healthy and five asthmatic children was 105 seconds (range 40-75 seconds in healthy children and 75-105 seconds in asthmatic children). The five asthmatic children, aged 3-7 years, had values of FRC ranging from $110 \%$ to $150 \%$ of the predicted value. All nine children remained attached to the spirograph in the FRC mode for at least two minutes after equilibration time was achieved; within that period the change in volume never exceeded $20 \mathrm{ml}$. For the remainder of the study the equilibration time was therefore defined in terms of a volume change of less than $20 \mathrm{ml}$ within 30 seconds.

Asthmatic patients with symptoms (group 5) required a significantly longer time to reach equilibration (mean 96 seconds, range 90-105s) than those with the mildest asthma (group 1: mean 76, range $60-90 \mathrm{~s} ; \mathrm{p}<0.01)$. The time to equilibration was also affected by the severity of disease, groups $3 \stackrel{\vec{\sim}}{\rightarrow}$ and 4 requiring a longer time to equilibration (meano $85 \mathrm{~s}$ ) than group 1 (mean $76 \mathrm{~s}$ ); but this difference did not reach statistical significance.

REPRODUCIBILITY
Six of the eight children in whom reproducibility studies were performed were symptom free at the time? of measurement. The intrasubject coefficient of vari- $\vec{\omega}$ ation in six successive measurements in each child $\stackrel{\omega}{\circ}$ ranged from $2.7 \%$ to $8.4 \%$ (FRC) and from $4.9 \%$ to $8.9 \%$ (CRS). Reproducibility in the two youngest. children ( 2.9 and 3.0 years) was similar to that in the ${ }_{V}^{N}$ older children (table 1).

Two of the children, twins aged $3 \cdot 1$ years, devel-O oped symptoms by the second day. Their resultso therefore were excluded from the reproducibility study. They showed deterioration in lung function when they had symptoms. In one twin compliance decreased from 50 to $23 \mathrm{ml} / \mathrm{cm} \mathrm{H}_{2} \mathrm{O}$ and $\mathrm{FRC}_{\vec{\bullet}}$ increased from 674 to $985 \mathrm{ml}$ and in the other CRSY decreased from 57 to $38 \mathrm{ml} / \mathrm{cm} \mathrm{H}_{2} \mathrm{O}$ while $\mathrm{FRC}_{\square}$ increased from 693 to $837 \mathrm{ml}$.

\section{CRS AND FRC}

Measurements of both FRC and CRS were obtainedő in 27 girls (median age 5.2, range $2 \cdot 5-7 \cdot 9$ years) and $\mathbb{Q}$ 53 boys (median age $4 \cdot 7$ years, range $2 \cdot 2-7 \cdot 9$ ). In six $\vec{\circ}$ children only FRC measurements were made. These 3 six children in whom measurements of CRS were not? possible were all boys aged $6 \cdot 0-7 \cdot 5$ years; they eithero would not remain attached to the spirometer long enough to perform both measurements or breathedo irregularly on addition of the weight.

Most of the asthmatic children had higher FRCo values (fig 2) than our previous normal population There was a trend for increasing severity of asthma, as reflected by an increased need for medication, to be associated with increasing mean FRC (fig 2). Com-윽 parisons between groups showed significantly greater values of FRC in those with the most severe and? symptomatic asthma (groups $3,4,5$ ) than in the chil ț dren in treatment group $1(\mathrm{p}<0.01)$.

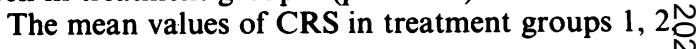

Results of reproducibility studies, with coefficients of variation in parentheses

\begin{tabular}{|c|c|c|c|c|}
\hline \multicolumn{3}{|c|}{ Patient details } & \multicolumn{2}{|c|}{ Results of measurements } \\
\hline Age $(y)$ & Height $(\mathrm{cm})$ & Treatment score ${ }^{*}$ & $F R C(m l)$ & $\mathrm{CRS}\left(\mathrm{ml} / \mathrm{cm} \mathrm{H} \mathrm{H}_{2} \mathrm{O}\right)$ \\
\hline $\begin{array}{l}2.9 \\
3.0 \\
4.9 \\
5.2 \\
5.7 \\
6.1\end{array}$ & $\begin{array}{r}94 \\
92 \\
110 \\
111 \\
110 \\
119\end{array}$ & $\begin{array}{l}2 \\
4 \\
1 \\
2 \\
3 \\
2\end{array}$ & $\begin{array}{l}543(6 \cdot 7) \\
590(2 \cdot 7) \\
801(8 \cdot 4) \\
846(8 \cdot 3) \\
930(4 \cdot 7) \\
943(5 \cdot 9)\end{array}$ & $\begin{array}{l}20.5(8.9) \\
32.9(4.9) \\
53.4(7.0) \\
55.2(8.7) \\
44.5(7.6) \\
40.2(7.8)\end{array}$ \\
\hline
\end{tabular}


FRC

CRS
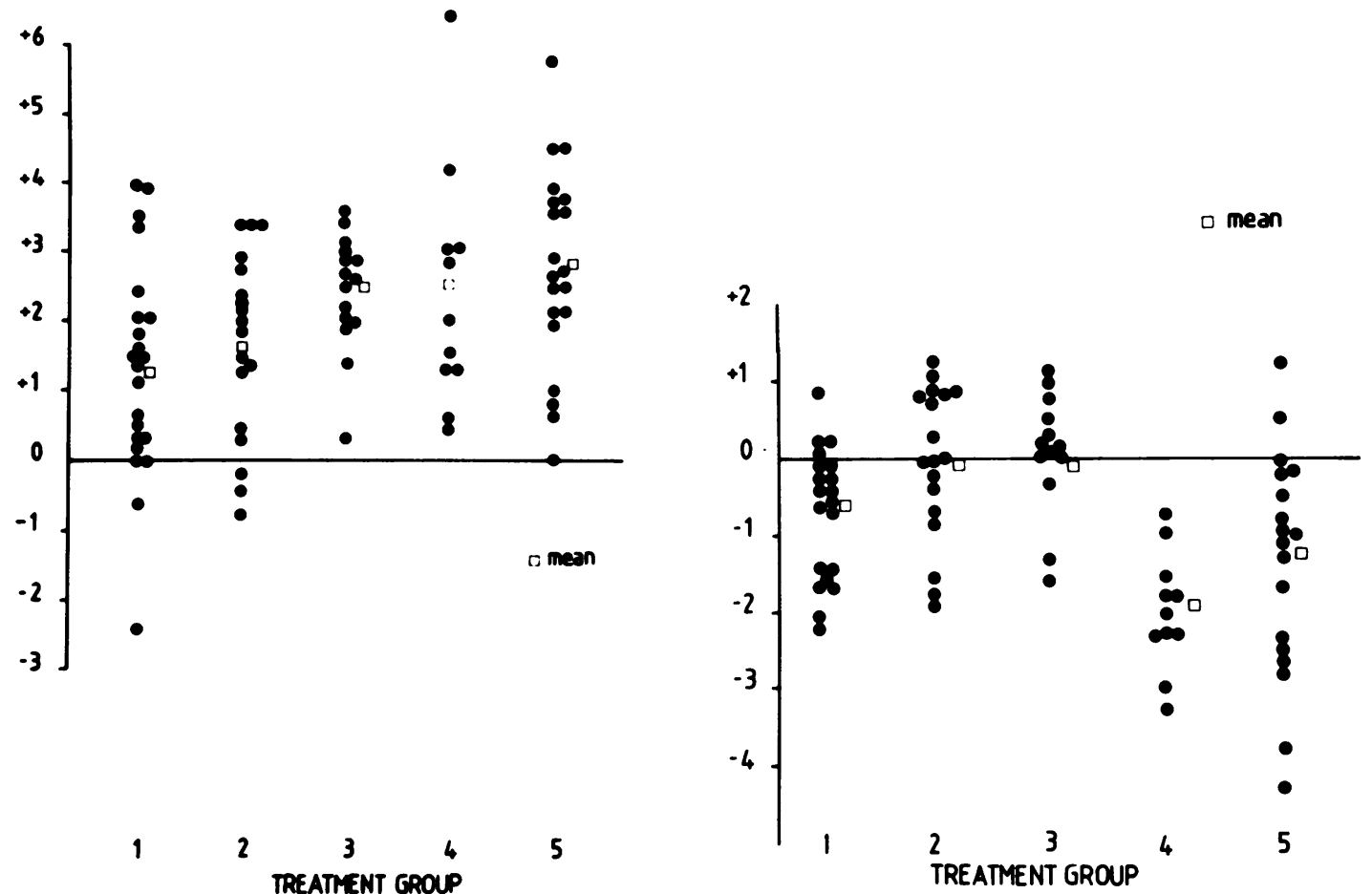

Fig 2 Measurements of functional residual capacity (FRC) and compliance of the respiratory system (CRS) system for each patient, represented as z scores, plotted according to treatment group. The open squares represent the mean values for each group. All treatment groups had a higher mean FRC than the normal population. ${ }^{8}$ CRS values for treatment groups 1 , 2 , and 3 are similar to values for the normal population; in groups 4 and 5, however, CRS was significantly less than normal.

and 3 did not differ significantly from our previous normal population. ${ }^{8}$ Between group comparisons showed a significantly lower CRS in those with the most severe (group 4, p $<0.001$ ) and symptomatic asthma (group 5, p $<0.01$ ) than in the children in treatment groups 1,2 , and 3 (fig 2).

\section{PEAK FLOW MEASUREMENTS}

Ten of the 20 children aged 4-6 years and 16 of 20 aged 2-4 years were unable, even with practice, to perform reproducible peak flow manoeuvres. We could not therefore make a useful comparison of peak flow with FRC and CRS.

\section{Discussion}

About $11 \%$ of British schoolchildren suffer from asthma. ${ }^{14}$ In children and adults lung function studies are extremely useful in establishing the diagnosis of asthma by showing variability of airways obstruction, describing the pattern and severity of asthma, and monitoring the response to treatment. Unfortunately, traditional methods of measuring lung function in asthma become increasingly unreliable in children aged less than 7 years, but by this age most of those with childhood asthma will have had their first attack. ${ }^{15}$

Peak flow has been used in young children to assess bronchodilator response and confirm reversibility. Its main advantage is simplicity, which means that the test can be performed repeatedly, and at home. ${ }^{13}$ Peak expiratory flow, however, is influenced mainly by the calibre of the larger airways and may not detect abnormalities of small airway function. ${ }^{16}$ Although children as young as 2 years can perform a peak flow manoeuvre, they require practice and some tend initially to close the glottis, producing an inaccurate recording. ${ }^{17}$ At least one author has suggested that peak flow recordings are unlikely to be sufficiently reliable under the age of 5 years. ${ }^{18}$ We found that children under 5 years rarely perform this manoeuvre successfully on their first visit to the laboratory. Most 
who were successful had already taken part in other asthma studies and had been educated in the performance of the manoeuvre over several months.

Forced oscillation, on the other hand, requires little or no cooperation from the child. With this technique total respiratory impedance (or resistance) can be calculated from the relationship between pressure and flow at the mouth when flow is produced by a sinusoidal wave. In older children this method gives reproducible results with a coefficient of variation of $12 \%$ but there is a wide scatter of results in 4 and 5 year olds. ${ }^{6}$ The technique has been used to investigate response to treatment in preschool asthma. ${ }^{1920}$ It is, however, influenced by upper respiratory tract infections, which are common in young children, and it gives a value of resistance unrelated to lung volume. A major criticism is that in the presence of respiratory disease, such as asthma, the lung may not act as a single unit and therefore there is no one resonant frequency. As a consequence, flow resistance will be underestimated.

The present results show that the combined technique of helium gas dilution and weighted spirometry is not only well tolerated in such young asthmatic children but also reproducible. Despite the impairment of gas mixing ${ }^{21}$ that occurs in asthma, we found that the time to equilibration during the measurement of FRC by helium gas dilution was only about twice that quoted in most studies for normal subjects (for example, 20-60 seconds ${ }^{22}$ and 45 seconds ${ }^{23}{ }^{24}$ ), only one study giving a longer equilibration period of three minutes. ${ }^{25}$ In children with symptoms we found that the time to equilibration was significantly longer, but still considerably less than the time (over five minutes) observed in a study on adults with severe asthma. ${ }^{26}$ This last study, however, used a more stringent definition of equilibration, less than $0.01 \%$ of change over one minute.

In the present study measurement of FRC was well tolerated in all the children tested, no practice was required, and the level of reproducibility was well within the range quoted for other methods in normal children. ${ }^{67} \mathrm{~A}$ possible source of error is the problem of leaks, but by combining the two techniques as described leaks are easily detected (fig 1). Another possible source of error, especially in smaller children, is that the circuit volume is relatively large in comparison with the FRC. The spirometer bell always resets to a constant volume at the beginning of each test. The addition of a child's FRC of $600 \mathrm{ml}$ would make a change of about $10 \%$ to the total circuit volume. We have shown, however, both in normal ${ }^{8}$ and in young asthmatic children that the measurement of FRC is very reproducible.

Measurement of CRS by weighted spirometry assumes relaxation of the chest wall at the end expiration during positive pressure breathing. Electromyographic studies during application of this tech $-\frac{5}{-}$ nique have been reported for only one infant, but in? this child no expiratory muscle activity was음 detected. ${ }^{27}$ In our previous study attempts to obtain? electromyographic recordings had to be abandoned $\mathbb{Q}$ because of the difficulty of obtaining interference frees signals and because of poor tolerance of the increasedduration of the test. ${ }^{8}$ Traces were inspected therefore. for changes in respiratory pattern that would indicate $\vec{\omega}$ active expiration. In this study, on the basis of such criteria, results from three of the 86 children had to be excluded. In three other children it was impossible to: make measurements of compliance because of theirlimited cooperation.

From these measurements we have been able to show that some of these very young asthmatic chil-음 dren have a significantly raised FRC and reduction inrespiratory compliance. Similar observations have been made in older asthmatic subjects by several groups. ${ }^{1128-30}$ During an acute attack of asthma응 FRC may be greater than the total lung capacity after. recovery. ${ }^{10}$ Compliance, which may dimish during and acute episode in adults and older children, ${ }^{31-34}$ mays revert to normal after resolution of symptoms. ${ }^{350}$ Using this combined technique, we have been able too demonstrate improvements both in FRC (decrease) and in compliance (increase) after bronchodilator treatment during an acute asthma attack. ${ }^{36}$

This study has shown that mean FRC progressively increases with increasing severity of asthma. Af significant reduction in CRS, however, was seen only in children with chronic persistent disease. We have also shown that these two techniques are well toler ated and reproducible in most young asthmatic children.

Jenny Pool is supported by Children Nationwide Medical Research Fund. We acknowledge the advices and help of Dr P Helms and Dr J Stocks in the development of this technique. We thank Mrs Angelap $\mathrm{McPherson}$ for secretarial assistance.

\section{References}

1 Strachan DP The prevalence and natural history of wheezing in early childhood. $J R$ Coll Gen Pract 1975;35:182-4.

2 MacKenzie SA, Edmunds AT, Godfrey S. Status asthmaticus-a one year study. Arch Dis Child 1979;54:581-6.

3 Khot A, Burn R, Lenney C, Lenney W. Seasonal vari $\frac{0}{\mathbb{D}}$ ation and time trends in childhood asthma in England? and Wales. Br Med J 1984;289:235-7.

4 Pearce JL, Wesley HMM. Children with asthma: will nebulised salbutamol reduce hospital admissions? Br Med J 1985;290:595-7. 
5 Glass J, Archer LNJ, Adams W, Simpson H. Nebulised cromoglycate, theophylline and placebo in pre-school asthmatic children. Arch Dis Child 1981;56:648-51.

6 Cogswell JJ. Forced oscillation technique for determination of resistance to breathing in children. Arch Dis Child 1973;48:259-66.

7 Milner AD, Ingram D. Peak expiratory flow rates in children under 5 years of age. Arch Dis Child 1970;45: 780-2.

8 Greenough A, Stocks J, Nothen U, Helms P. Total respiratory compliance and functional residual capacity in young children. Pediatric Pulmonology 1986;2:321-7.

9 Woolcock AJ, Read J. Lung volumes in exacerbations of asthma. Am J Med 1966;41:259-73.

10 Woolcock AJ, Read J. Improvement in bronchial asthma not reflected in forced expiratory volume. Lancet 1965;ii:1323-5.

11 Mansell A, Dubrawsky C, Levison H, et al. Lung mechanics in antigen induced asthma. J Appl Physiol 1974;37:297-301.

12 Warner JO. Significance of late reactions after bronchial challenge with house dust mite. Arch Dis Child 1976;51:905-11.

13 Steiner N, Phelan PD. Physiological assessment of severe chronic asthma in children. Respiration 1978;35:30-6.

14 Lee DA, Winslow NR, Speight ANP, Hey EN. Prevalence and spectrum of asthma in childhood. Br Med J 1983;286:1253-6.

15 Williams H, McNicol KN. Prevalence, natural history and relationship of wheezy bronchitis and asthma in children. An epidemiological study. $\mathrm{Br} \mathrm{Med} J$ 1969;iv:321-5.

16 Mead J, Turner JM, Macklem PT, Little JP. Significance of the relationship between lung recoil and maximum expiratory flow. J Appl Physiol 1967;22:95-108.

17 Lenney W, Milner AD. Recurrent wheezing in the preschool child. Arch Dis Child 1978;53:468-73.

18 Silverman $M$, Wilson $N$. Bronchial responsiveness in children: a clinical view. In: Milner AD, Martin RJ, eds. Neonatal and paediatric respiratory medicine. London: Butterworths, 1985:161.

19 Groggins RC, Milner AD, Stokes GM. Bronchodilator effects of clemastine, ipratropium bromide and salbutamol in pre-school children with asthma. Arch Dis Child 1981;56:342-4.

20 Lenney W, Milner AD. At what age do bronchodilators work? Arch Dis Child 1978;53:530-5

21 Bentivoglio LG, Beerel F, Bryan AC, Stewart PD, Rose B, Bates DV. Regional pulmonary function studied with xenon ${ }^{133}$ in patients with bronchial asthma. $J$ Clin Invest 1963;42:1193-200.

22 Taussig LM, Harris TR, Lebowitz MD. Lung function in infants and young children. Am Rev Respir Dis 1977;116:233-9.

23 DeMuth GR, Howatt WF, Hill BM. Lung volumes. Pediatrics 1965;53:165-77.

24 Krauss AN, Auld PAM. Measurement of functional residual capacity in distressed neonates by helium rebreathing. J Pediatr 1970;77:228-32.

25 Cogswell JJ, Hull D, Milner AD, Normal AP, Taylor B. Lung function in childhood. $\mathrm{Br} J$ Dis Chest 1975;69:118-24.

26 Meisner P, Hugh-Jones P. Pulmonary function in bronchial asthma. Br Med J 1968;i:470-5.

27 Tepper RS, Pagtakhan RD, Taussig LM. Non-invasive determination of total respiratory system compliance in infants by the weighted spirometer method. Am Rev Respir Dis 1984;130:461-6.

28 Gold WM, Kaufman HS, Nadel JA. Elastic recoil of the lungs in chronic asthmatic patients before and after therapy. J Appl Physiol 1967;23:433-8.

29 Marshall $R$. The physical properties of the lungs in relation to the subdivision of lung volume. Clin Sci 1957;16:507-12.

30 Wells RE. Mechanics of respiration in bronchial asthma. Am J Med 1959;26:384-93.

31 Bäcklund L, Irnell L. Compliance in bronchial asthma. Acta Med Scand 1968;183:281-7.

32 McIlroy MB, Marshall R. The mechanical properties of the lung in asthma. Clin Sci 1956;15:345-51.

33 Peress L, Sybrecht G, Macklem PT. The mechanism of increase in total lung capacity in acute asthma. $\mathrm{Am} \mathrm{J}$ Med 1976;61:165-9.

34 Tooley WH, Demuth G, Nadel JA. The reversibility of obstructive changes in severe childhood asthma. J Pediatr 1965;66:517-24.

35 McFadden ER, Lyons HA. Airways resistance and uneven ventilation in bronchial asthma. J Appl Physiol 1968;25:365-70.

36 Greenough A, Loftus BG, Pool J, Price JF. Response to bronchodilators assessed by lung mechanics. Arch Dis Child 1986;61:1020-3. 